\title{
Dioxolanylium Ions Derived from Carbohydrates. II
}

\author{
STEFFEN JACOBSEN and CHRISTIAN PEDERSEN
}

Department of Organic Chemistry, Technical University of Denmark, DK-2800 Lyngby, Denmark

\begin{abstract}
Reaction of methyl 2,3:4,6-di- $O$-benzylidene$\alpha$-D-mannopyranoside with triphenylmethyl fluoroborate gave the 2,3-benzoxonium ion (2); the 4,6-benzylidene group did not react. A similar treatment of 3-O-benzoyl-5,6-O. benzylidene-1,2-O-isopropylidene- $\alpha$-D-glucofuranose gave the 5,6-benzoxonium ion $(5)$, and $1,2: 3,4$-di- $O$-benzylidene- $\beta$-D-arabinopyranose yielded the 3,4-benzoxonium ion (11). In the latter case no hydride abstraction took place from the 1,2-benzylidene group. A study of a number of compounds showed that 4,6-, 3,5-, and 1,2-O-benzylidene groups, attached to pyranose or furanose rings, did not undergo hydride abstraction with triphenylmethyl fluoroborate. The reactions of the ions 2,5 , and 11 with water and with bromide ions were studied.
\end{abstract}

In the preceding paper ${ }^{1}$ it was shown that benzoxonium ions could be generated by reaction of benzylidene derivatives with triphenylmethyl fluoroborate in acetonitrile solution. The dioxolanylium ring was shown to undergo cis-opening when hydrolysed whereas reaction with bromide ions lead to trans-opening and formation of bromo-deoxy sugars. In the present paper further examples of these reactions are described, mainly in the hexose series, and the behaviour of various types of benzylidene compounds towards triphenylmethyl fluoroborate has been investigated.

Treatment of methyl 2,3:4,6-di-O-benzylidene- $\alpha$-D-mannopyranoside (1) with triphenylmethyl fluoroborate in acetonitrile gave the 2,3-benzoxonium ion (2) in quantitative yield after $16 \mathrm{~h}$. The ion was quite stable and its NMR spectrum could be measured in deuterioacetonitrile (Table 1). On prolonged reaction with triphenylmethyl fluoroborate a slow decomposition took place, but no hydride abstraction from the 4,6-O-benzylidene group was observed. Lack of reactivity of certain types of benzylidene derivatives was found in a number of other cases. Thus the following compounds could not be induced to react with triphenylmethyl fluoroborate in acetonitrile: methyl 2,3-di-O-acetyl-4,6-O-benzylidene- $\alpha$-Dglucopyranoside, methyl 2,3-di-O-benzoyl-4,6$O$-benzylidene- $\alpha$-D-galactopyranoside, $\quad 3,5-O$ benzylidene-6-O-benzoyl-1,2- $O$-isopropylidene$\alpha$-D-glucofuranose, 1,2:4,6-di- $O$-benzylidene-3$O$-benzoyl- $\alpha$-D-glucopyranose, and 1,2:3,5-di-O benzylidene-6-O-benzoyl- $\alpha$-D-glucofuranose.

From these results it appears that benzoxonium ions with 6-membered rings cannot be formed under the conditions used; the latter two examples furthermore show that 1,2-benzoxonium ions are not formed. However, while 1,2-O-benzylidene groups were isomerized by triphenylmethyl fluoroborate to mixtures of endo and exo isomers 4,6-O-benzylidene groups were completely unaffected. This was further confirmed by treating 1,2:3,4-di- $O$-benzylidene$\beta$-D-arabinopyranose (10) with triphenylmethyl fluoroborate which gave the 3,4-benzoxonium ion (11) as the sole product. NMR spectra of the two diastereomers of 11 are shown in Table 1. The dibenzoxonium ion which could be formed by hydride abstraction from 11 was not detected. It is known to be stable in anhydrous hydrogen fluoride solution. ${ }^{2}$

Treatment of 3-O-benzoyl-5,6-O-benzylidene1,2-O-isopropylidene- $\alpha$-D-glucofuranose (4) with triphenylmethyl fluoroborate rapidly gave the benzoxonium ion (5) as seen from its NMR spectrum in deuterioacetonitrile (Table 1). The corresponding 3-O-mesylated ion was obtained by Hanessian and Staub. ${ }^{3}$ Barton et al..$^{4}$ have shown that isopropylidene groups will react with triphenylmethyl fluoroborate. This reac- 


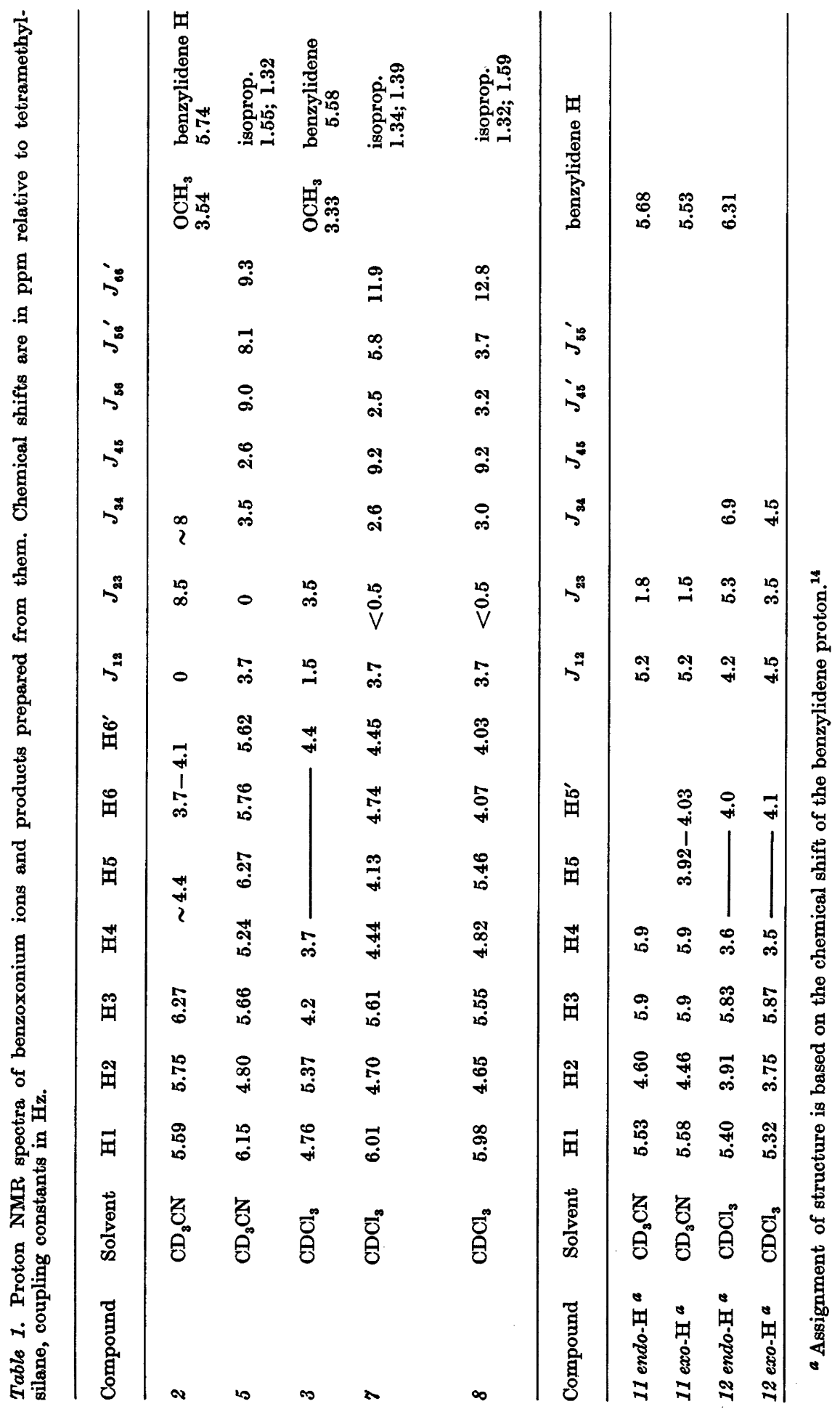

Acta Chem. Scand. B 28 (1974) No. 9 


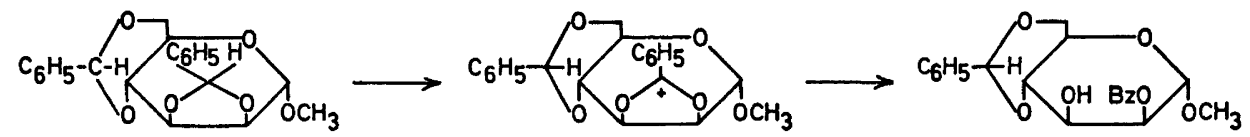

1

2

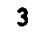

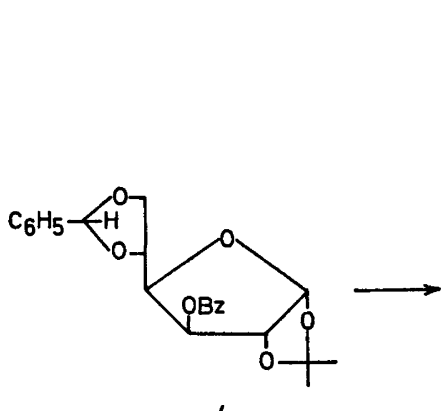

4

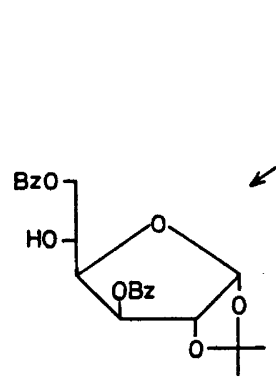

7

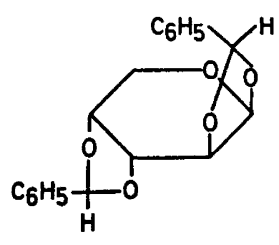

10
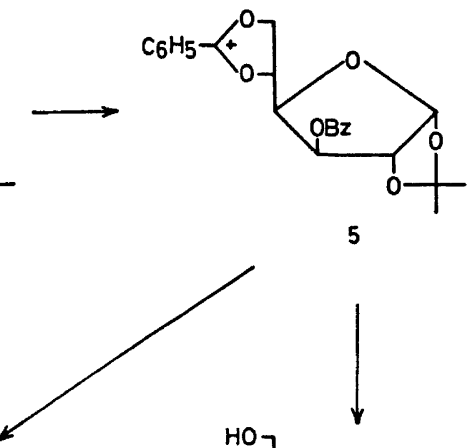

5

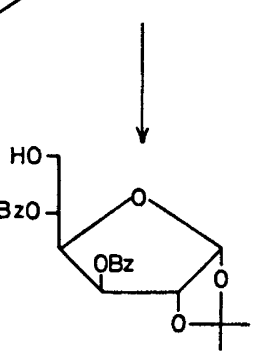

8

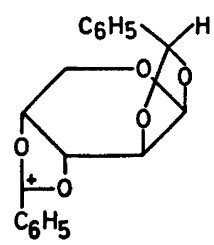

11

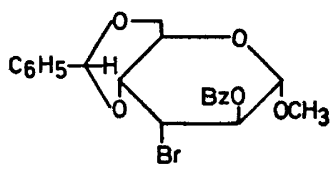

6
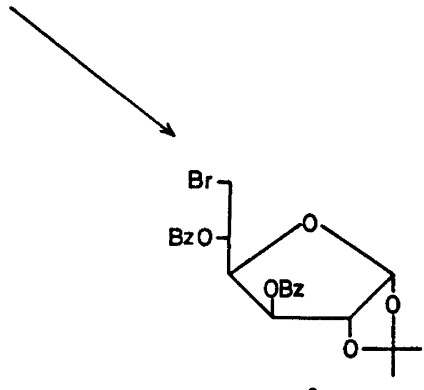

9

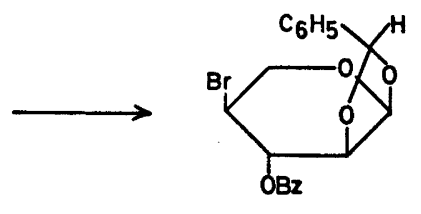

12 tion is, however, slower than the reaction with benzylidene groups and it was not observed. When the benzoxonium ion (5) was kept in acetonitrile solution in the presence of excess triphenylmethyl fluoroborate for several days a slow decomposition took place.

The benzoxonium ions were reacted with water and with bromide ions as in the preceding paper. ${ }^{1}$ Treatment of 2 with water gave the 2-O-benzoate (3), with an axial $O$-benzoyl group, as the sole product, in agreement with the results of King and Allbutt. The 5,6benzoxonium ion (5) gave a mixture of the 6 $O$-benzoate $(7)$ and the 5-O-benzoate $(8)$ on hydrolysis.

Reaction of 2 with bromide ions lead to trans-opening of the dioxolanylium ring and gave the 3-bromo-3-deoxy-altroside (6) as the only product. The formation of the transdiaxial product is in agreement with the results 
that King and Allbutt ${ }^{6}$ found for nucleophilic opening of dioxolanylium rings fused to bicyclic systems. The 5,6-benzoxonium ion (5) gave only the 6-bromo-derivative $(9)$ on reaction with bromide ions. ${ }^{3}$ Finally, the benzoxonium ion (11) when treated with bromide ions gave the 4-bromo-4-deoxy-I-xylose derivative (12) as a mixture of the two diastereomers.

\section{EXPERIMENTAL}

For details of chromatography and NMR spectroseopy see the preceding paper. ${ }^{1}$

Methyl 2,3:4,6-di-O-benzylidene- $\alpha$-D-mannopyranoside (1). Methyl $\alpha$-D-mannopyranoside $(9.7 \mathrm{~g})$ and benzaldehyde (11.5 g) were boiled for $10 \mathrm{~h}$ with $p$-toluenesulfonic acid $(100 \mathrm{mg}$ ) in chloroform $(200 \mathrm{ml})$ with a Soxhlet extractor containing $50 \mathrm{~g}$ of $4 \AA$ molecular sieves. The solution was then washed with aqueous sodium hydrogencarbonate and water, dried and evaporated. The residue was crystallized from ethanol-chloroform to give $8.5 \mathrm{~g}$ of 1 . The mother liquor was evaporated and the residue was dissolved in chloroform and boiled for $1 \mathrm{~h}$ with $p$-toluenesulfonic acid $(100 \mathrm{mg})$. Work up as described above gave 3.4 $\mathrm{g}$ of 1 . After an ad. ditional equilibration the total yield of 1 was $13.7 \mathrm{~g}, \mathrm{~m}$.p. $160-175^{\circ} \mathrm{C}$. One recrystallization from ethanol-chloroform gave $11.9 \mathrm{~g}$ of a product with m.p. 176-177 ${ }^{\circ} \mathrm{C}$ (reported ? m.p. $\left.180-181^{\circ} \mathrm{C}\right)$.

Conversion of benzylidene derivatives to hydroxy-ben. zoates

The benzoxonium ions were prepared by reaction of the benzylidene derivatives with a $10-25 \%$ molar excess of triphenylmethyl fluoroborate in dry acetonitrile at room temp. Hydrolysis and chromatography was performed as described in the preceding paper. ${ }^{1}$

Methyl 2,3:4,6-di-O-benzylidene- $\alpha$-D-mannopyranoside (1) $(520 \mathrm{mg}$ ) gave the benzoxonium ion (2) after reaction with triphenylmethyl fluoroborate for $16 \mathrm{~h}$. Hydrolysis and chromatography yielded $364 \mathrm{mg}(67 \%)$ of methyl 2$O$-benzoyl-4,6- $O$-benzylidene- $\alpha$-D-mannopyranoside (3) as a syrup, $[\alpha]_{D^{21}}-33.8^{\circ}\left(c 1.3, \mathrm{CHCl}_{3}\right)$. (Found: $\mathrm{C}$ 65.13; $\mathrm{H}$ 5.82. Calc. for $\mathrm{C}_{21} \mathrm{H}_{22} \mathrm{O}_{7}$ : C 65.27; H 5.74). An NMR spectrum (Table 1) proved the structure. Debenzoylation with sodium methoxide in methanol and recrystallization from ethanol-water gave methyl 4,6-O-benzylidene- $\alpha$-D-mannopyranoside, m.p. $145-145.5^{\circ} \mathrm{C}$ (reported ${ }^{7}$ m.p. $146-147^{\circ} \mathrm{C}$ ). A mixed m.p. with an authentic sample gave no depression.

3-O-Benzoyl-5,6-O-benzylidene-1,2-0-isopropylidene- $\alpha-\mathrm{D}$-glucofuranose $(4)^{8}(533 \mathrm{mg})$ gave the benzoxonium ion (5) after reaction with triphenylmethyl fluoroborate for $1 \mathrm{~h}$. Hydrolysis and chromatography yielded two products. The fast moving fraction ( $183 \mathrm{mg}, 33 \%$ ) was 3,6-di- $O$-benzoyl-1,2- $O$-isopropylidene- $\alpha$-D-glucofuranose (7), m.p. $108-110^{\circ} \mathrm{C},[\alpha]_{\mathrm{D}^{20}}-4.4^{\circ}$ (c $1.7, \mathrm{CHCl}_{3}$ ), (reported ${ }^{\circ}$ m.p. $108^{\circ}-109^{\circ} \mathrm{C}$, $\left.[\alpha]_{\mathrm{D}}-4.6^{\circ}\right)$. The slow moving fraction $(213 \mathrm{mg}$, $38 \%$ ) was the 3,5 -di- $O$-benzoate ( 8 ) as a syrup, $[\alpha]_{D}{ }^{21}-111.3^{\circ}\left(c\right.$ 1.6, $\mathrm{CHCl}_{3}$ ). (Found: $\mathrm{C}$ 64.34; $\mathrm{H}$ 5.77. Calc. for $\mathrm{C}_{23} \mathrm{H}_{24} \mathrm{O}_{8}$ : $\mathrm{C}$ 64.48; $\mathrm{H}$ 5.65). Benzoylation of (8) with benzoyl chloride in pyridine gave $3,5,6$-tri- $O$-benzoyl-1,2- $O$-isopropylidene- $\alpha$-D-glucofuranose, m.p. $118-120^{\circ} \mathrm{C}$ (reported ${ }^{10}$ m.p. $119-120^{\circ} \mathrm{C}$ ). A mixed m.p. with an authentic sample gave no depression. Conversion of benzylidene
derivatives to bromo-deoxy-
benzogtes

The benzoxonium ions were prepared as described above and treated with dry tetraethylammonium bromide (3 molar equiv.) in acetonitrile for $2 \mathrm{~h}$. Work up and chromatography as described in the preceding ${ }^{1}$ paper gave the products.

Methyl 2,3:4,6-di-O-benzylidene- $\alpha$-D-mannopyranoside (1) $(552 \mathrm{mg})$ gave $388 \mathrm{mg}(50 \%)$ of methyl 2-O-benzoyl-4,6-O-benzylidene-3bromo-3-deoxy- $\alpha$-D-altropyranoside (6). Crystallization from ethyl acetate-pentane gave the pure product, m.p. $134-136^{\circ} \mathrm{C}$. (Found: C 56.25; $\mathrm{H} 4.62 ; \mathrm{Br}$ 17.91. Calc. for $\mathrm{C}_{21} \mathrm{H}_{21} \mathrm{BrO}_{6}$ : C 56.13; H 4.71; $\mathrm{Br}$ 17.79). The product was identical with a sample prepared by benzoylation of methyl 4,6-O-benzylidene-3-bromo-3deoxy $-\alpha$-D-altropyranoside, 11 m.p. 136.5 - 137.5 ${ }^{\circ} \mathrm{C},[\alpha]_{\mathrm{D}^{21}}+1.6^{\circ}$ (c 1.5, $\mathrm{CHCl}_{3}$ ). A mixed m.p. gave no depression.

In a separate experiment $3.3 \mathrm{~g}$ of 1 was converted to the 2,3 -benzoxonium ion (2) which was treated with tetraethylammonium bromide to give the bromo-compound $(6)$ in acetonitrile solution. Stirring with saturated aqueous sodium hydrogencarbonate $(50 \mathrm{ml})$ for $30 \mathrm{~min}$ gave a crystalline precipitate which was filtered off and washed with water. Extraction with pentane $(3 \times 50 \mathrm{ml})$ removed most of the triphenylmethane. The product was then dissolved in ethyl acetate $(50 \mathrm{ml})$ and treated with activated carbon. Evaporation of the ethyl acetate to $c a .10 \mathrm{ml}$ and addition of pentane $(40 \mathrm{ml})$ precipitated $1.75 \mathrm{~g}(43 \%)$ of $6, \mathrm{~m} . \mathrm{p}$. $135-137^{\circ} \mathrm{C}$. One recrystallization from ethyl acetate - pentane gave $1.60 \mathrm{~g}$, m.p. 136$138{ }^{\circ} \mathrm{C},[\alpha]_{\mathrm{D}}{ }^{20}+1.2^{\circ}$ (c $\left.1.2, \mathrm{CHCl}_{3}\right)$.

3-0-Benzoyl-5,6-O-benzylidene-1,2-0-isopropylidene- $\alpha$-D-glucofuranose (4) (454 $\mathrm{mg})$ gave after chromatography $427 \mathrm{mg}(79 \%)$ of 3,5 -di$O$-benzoyl-6-bromo-6-deoxy-1,2-O-isopropylidene- $\alpha$-D-glucofuranose (9) as a syrup, $[\alpha]_{D^{21}}$ $\left.-114.5^{\circ}(c) 1.2, \mathrm{CHCl}_{3}\right)$. (Found. C 56.41; $\mathrm{H}$ 4.78; $\mathrm{Br}$ 16.13. Calc. for $\mathrm{C}_{23} \mathrm{H}_{23} \mathrm{O}_{7} \mathrm{Br}$ : $\mathrm{C} 56.22$;

Acta Chem. Scand. B 28 (1974) No. 9 
H 4.72; $\mathrm{Br}$ 16.26). A product obtained by benzoylation of 5-O-benzoyl-6-bromo-6-deoxy1,2-O-isopropylidene- $\alpha$-D-glucofuranose ${ }^{12}$ had $[\alpha]_{D^{21}}-119.8^{\circ}\left(c 1.4, \mathrm{CHCl}_{3}\right)$. NMR spectra of the two products were identical.

1,2:3,4-Di-O-benzylidene- $\beta$-D-arabinopyran-

ose $^{13}$ (10) (508 $\mathrm{mg}$ ) gave the 3,4-benzoxonium ion (11) after treatment with triphenylmethyl fluoroborate for $4 \mathrm{~h}$ in acetonitrile solution. Reaction with tetraethylammonium bromide and work up as described above yielded $324 \mathrm{mg}$ $(51 \%)$ of a mixture of the diastereomeric 3 . $O$-benzoyl-1,2-O-benzylidene-4-bromo-4-deoxy$\alpha$-L,-xylopyranoses (12). Crystallization from ethyl acetate $(3 \mathrm{ml})$-pentane $(10 \mathrm{ml})$ gave $102 \mathrm{mg}$, m.p. $124-125^{\circ} \mathrm{C}$. Recrystallization gave the pure endo- $\mathrm{H}$ isomer, m.p. $125-126^{\circ} \mathrm{C}$, $[\alpha]_{\mathrm{D}}{ }^{21}-43.3^{\circ}$ (c 1.7, $\mathrm{CHCl}_{3}$ ). (Found: C 56.43; $\mathrm{H} 4.31$; $\mathrm{Br}$ 19.72. Calc. for $\mathrm{C}_{19} \mathrm{H}_{17} \mathrm{BrO}_{5}$ : C 56.31; $\mathrm{H} 4.22 ; \mathrm{Br} 19.72$ ). The exo-H isomer could not be obtained pure, but preparative TLC (benzene) gave a product which contained $80 \%$ exo-H isomer, allowing it to be identified through its NMR spectrum (Table 1).

Microanalyses were performed by Dr. A. Bernhardt, Mikroanalytisches Laboratorium or by Novo Microanalytical Laboratories.

\section{REFERENCES}

1. Jacobsen, S. and Pedersen, C. Acta Chem. Scand. $B 28$ (1974) 866.

2. Pedersen, C. Acta Chem. Scand. 22 (1968) 1888.

3. Hanessian, S. and Staub, A. P. A. Tetrahedron Lett. (1973) 3551.

4. Barton, D. H. R., Magnus, P. D., Smith, G., Streckert, G. and Zurr, D. J. Chem. Soc. Perkin Trans 1 (1972) 542

5. King, J. F. and Allbutt, A. D. Can. J. Chem. 48 (1970) 1754.

6. King, J. F. and Allbutt, A. D. Can. J. Chem. 47 (1969) 1445.

7. Robertson, G. J. J. Chem. Soc. (1934) 330.

8. Levene, P. A. and Raymond, A. L. Ber. Deut. Chem. Ges. 66 (1933) 384.

9. Brigl, P. and Grüner, H. Ber. Deut. Chem. Ges. B 66 (1933) 1977.

10. Fischer, E. and Rund. C. Ber. Deut. Chem. Ges. 49 (1916) 88.

11. Richards, G. N., Wiggins, L. F. and Wise, W. S. J. Chem. Soc. (1956) 496.

12. Hanessian, S. and Plessas, N. R. J. Org. Chem. 34 (1969) 1053.

13. van Ekenstein, W. A. and Blanksma, J. J. Rec. Trav. Chim. Pays-Bas 25 (1906) 153.

14. Baggett, N., Buck, K. W., Foster, A. B. and Webber, J. M. J. Chem. Soc. (1965) 3401.

Received April 3, 1970. 